Monica Heller*

\title{
Scholarly committees as elite public action: The SSRC and the origins of sociolinguistics
}

https://doi.org/10.1515/ijsl-2020-2075

Abstract: Starting in the early 1950s, the SSRC cultivated interdisciplinary research into the role of language in culture and thought through its Committees on Psycholinguistics and Sociolinguistics. Here, Monica Heller examines how the latter committee (1963-1979) helped establish sociolinguistics in the United States, investigating the tensions between language, culture, and inequality. In exploring how the committee shifted focus from the developing world to marginalized groups in the United States, Heller addresses how the research agendas of these scholarly structures are influenced by the political dynamics or ideologies of their time, in this case the Cold War and decolonization.

Keywords: Social Science Research Council, committee on sociolinguistics, decolonization, development, cold war

When I was a graduate student in sociolinguistics at the University of California, Berkeley, in the late 1970s and early 1980s, I often heard about a mysterious body called "The Committee on Sociolinguistics." I will admit that this sounded slightly reminiscent of the French Revolutionary Committee of Public Safety (the one responsible for all that guillotining), and while in many ways the association is ridiculous, I will contend here that I wasn't entirely out of my mind.

Like other committees established by the Social Science Research Council (SSRC), the idea was to gather together a group of key US-based scholars to foster the emergence of a field understood to have relevance to matters of national political, economic, and social concern. As a graduate student, I was only dimly aware that somehow a small body of US-based scholars was setting the agenda for the field of sociolinguistics. This field was meant to develop scientific expertise on the basis of which to address contemporary tensions around language and inequality, and be relevant to public policy. That expertise was meant to be interdisciplinary; the committee brought together scholars from sociology, anthropology, social psychology, linguistics, demography, and political science.

*Corresponding author: Monica Heller, University of Toronto, Toronto, Canada, E-mail: monica.heller@utoronto.ca 
The Committee on Sociolinguistics was modeled on the Committee on Psycholinguistics (established in 1952, and closed shortly before the Committee on Sociolinguistics was suggested as a new direction). The Committee on Psycholinguistics can be understood as developing from wartime interests in propaganda or, more broadly, wartime and Cold War efforts to understand the mindset of enemies and to influence people's political thought. Not that these conditions (hot and cold war) were totally determining; it is no doubt fairer to say that intellectual genealogies - in this case, linking language, culture, and thought - made available regimented and regimenting techniques of analysis in which social, institutional, and state actors had an interest.

I contend it is worth thinking about these types of structures, such as closednetwork committees, in their historical context, viewing them as products of their time and linked to or influenced by contemporary political powers. In particular, how do these structures advance ideological causes by mediating between historically contingent state interests and population effects, through the legitimating action of select individuals - action devoted to what is understood as broad public interest? SSRC-sponsored committees, like this one (which existed from 1963 to 1979), did just that by developing frameworks and methods useful for investigating politically important questions. There was much less drama involved than in the French Revolution's Committee on Public Safety, of course, and arguably less concerted effect, but I think the notion of "committee" as elite public action is worth thinking about (I say this as someone who has been a member of a few herself).

While my first glimmerings of the existence of the Committee on Sociolinguistics was as a new recruit to what was self-consciously being constructed as a new, pioneering area of inquiry, many years later I began to wonder about the political and economic conditions in which the emergence of the field made sense; I found myself turning back to memories of talk about that committee. ${ }^{1}$

\footnotetext{
1 With the help of Ron Kassimir, I quickly found myself connected to the Rockefeller Archive Center, which holds the SSRC records as well as those of the Rockefeller Foundation. (The Rockefeller Foundation itself helped create the SSRC and has been one of its supporters since.) This essay is a result of two sessions of work in those archives, in 2016 and 2017, going through the complete set of archives related to the committee. Additionally, I would like to thank Margaret Hogan, lead archivist at the Rockefeller Archive Center.
} 


\section{The committee on sociolinguistics: Modernity and development in the $1960 \mathrm{~s}$}

The Committee on Sociolinguistics brought together a select group of scholars with experience in the area of "language," "culture," and "thought" (or "cognition"), which had long been understood as the basic elements for understanding humanity. These elements bounce back and forth in the tension between a "universal" understanding of all humans and the basis for empirically evident variation. This thread was already one which the Committee on Psycholinguistics had been exploring, focusing on cognition as a point of entry. But it was also evident that this variation across societies and cultures was mapped onto a range of categories of social difference (race, gender, sexuality, class, age, nation) constructed in the making of social inequality in the context of capitalism and colonialism. Thus the step from psycholinguistics to sociolinguistics is not difficult; if the first focused on the "thought" element of the canonical language-thought-culture triad, the second focused on the "culture" element.

Understanding how groups of people (especially nations or "ethnicities") thought, through the examination of language practices and forms, was necessarily linked to understanding the cultural forms in which these practices made sense and were reproduced. In the specific context of the Cold War, efforts to influence key emerging postcolonial states, like India or Indonesia, were conducted by both sides, using what were understood as techniques of modernization and development to turn former colonies into proper nation-states. In that frame, not only was it important to understand how people thought and why they acted the way they did; it was also important to confront problems of linguistic variation, notably multilingualism, understood to be obstacles to the making of a proper modern state (whether communist or capitalist). Language standardization, literacy, and the management of multilingualism were all understood to be pressing issues of state and scholarly concern in the overseas development context of Cold War competition. Thus the committee initially focused on the traditional Other, overseas, with members with relevant expertise. Members included people like John Gumperz, William Bright, and Charles Ferguson (the committee's first chair), who had experience in India or in Arabicspeaking countries, and Susan Ervin-Tripp (long the only female member, of a committee life total of two), interested in Japanese-American intercultural communication. 
It was not until the early 1970s that the committee started thinking systematically about domestic concerns. ${ }^{2}$ We can trace, then, how what can be understood as problems of Cold War neoimperialism and neocolonialism were framed together with similar "internal" problems: the legacies of empire on the North American continent and their effects on the construction and oppression of populations understood as "African American," "Native American," and "Chicano." Similar linkages had been made between concerns over international development and internal development that emerged from the civil rights movement - a kind of internal counterpart of independence movements in former European colonies - by the Ford Foundation in its language education projects. They funded curriculum development and teacher training in EFL (English as a Foreign Language) in places like Malaysia and the Philippines as well as Los Angeles - the latter aimed at children of immigrants (Fox 1975).

Committee members recognized how questions about linguistic variability and multilingualism pertained not only to countries in which the United States had a particular interest but also to matters closer to home. These concerns were connected to the civil rights movement, especially to the political mobilization for political, economic, and social equality of what were then called African American and Chicano communities. Here we see the importance of the expertise and interests of people like Dell Hymes (the second committee chair), whose worked focused on Native North America; Joshua Fishman, interested broadly in the emergent field of language policy and in immigrant communities and the "problem" of their integration; and William Labov, concerned about the treatment of Black Americans in urban development and in education.

At the same time, the committee debated how best to approach this USfocused set of phenomena. There was certainly consensus regarding one central problem: the ways in which linguistic differences from the norm of Standard English were widely understood to represent social, and even cognitive deficit, notably in education (a problem still very much with us today). Put simply, the standard language of school literacy was understood to be cognitively superior and absolutely necessary for success in school; both the multilingualism of Native Americans, immigrants and American Spanish-speakers, and English variants spoken by many Americans were understood to be obstacles to social mobility, and indeed socially, culturally, and even cognitively deficient. This way of thinking was understood by committee members to be discriminatory, since their empirical work had convinced them that linguistic forms and

2 As late as 1975 members remarked that their knowledge of variability in languages and cultures outside the United States was much deeper than their knowledge of that phenomenon within. 
practices might be different, but that didn't mean they were any less or more systematic or effective in the making of meaning. They thus agreed on the importance of developing and disseminating what were understood as emancipatory arguments about the universal characteristics of linguistic form and practice, as a way to counter views about linguistic inferiority that justified a range of discriminatory practices.

Members were less comfortable, the archives show, about addressing the political and economic sources of discrimination and inequality. Notably, in 1972, the committee committed to sponsoring a conference on Chicano sociolinguistics, which foundered when the Chicano studies scholars who agreed to be co-organizers suggested an overtly political dimension to the program. Some members of the committee found this "too political." It is hard to say exactly what members thought "too political" meant, given their willingness to enter debates about discrimination based on their expertise in the scientific description of linguistic form and practice, but it would seem they were uncomfortable with linking the term "Chicano sociolinguistics," and the occasion of the conference, to explicit demands for political rights and recognition. The committee also debated inviting African American and Chicano scholars to join (hitherto, as mentioned above, almost exclusively male, as well as white). Two or three names were discussed, and at least one invitation issued, but declined. By the late 1970s, the committee was having difficulty in focusing its mission, torn between universalist, interdisciplinary questions about how communication works and the always-pressing political problems of linguistic inequality and how to address them. In some sense, it had, perhaps, fulfilled its mission of institutionalizing an emergent field, having published an agenda-setting volume in $1972^{3}$ and founded a journal (Language in Society, with Hymes as editor) in the same year.

\section{Pending questions}

To my mind, this leaves us with several questions. The first asks what the longlasting effects on the field were of avoiding head-on confrontation of the nature and workings of linguistic inequality, which were part of public and policy debate at the time. This includes, as we have seen, the question of what kinds of people were understood to be agenda-setters, and who needed to find other

3 See Gumperz and Hymes (1991 [1972]). 
spaces for the development of their intellectual and political careers (if they were able to at all).

Second, from this vantage point we can see how the concerns of the committee were linked to Cold War competition for moral credibility, material wealth, and hence global domination between communism and liberal democracy. But what use was made of the work of the committee, especially by institutional actors connected to the SSRC (such as the Rockefeller Foundation), or to those connected to the centers where many of its members worked? We do have some (extra-archival) information on that front. For example, the committee was connected to several language policy think tanks: the Center for Applied Linguistics in Washington, DC (connected to Georgetown University and the US Foreign Service), the East-West Center in Honolulu (which brought together scholars from the United States and Asia, and provided policy proposals and analysis on this politically crucial region), and the Centre international de recherche sur le bilinguisme in Québec (connected to l'Université Laval and to language policy activities in Canada and Québec). The language policy network was also supported by the Ford Foundation's multinational grants mentioned above. Members of these networks have acted as expert witnesses in trials (e. g. regarding the provision of services to minority communities, or regarding how to interpret testimony) and developed curricula and bilingual education programs. But we still know little about how the ideas developed by the committee circulated in key decision-making sites, or how those ideas flowed through both the Rockefeller and Ford Foundations, and their government interlocutors.

Third, how then do we trace the (possible, even probable) unintended effects of the committee's work? How do we account for what has become part of the canon, and what has been sidelined although much attention was devoted to it at the time? One clear example was a project on grounded theory in which the same piece of data - a video of a doctoral thesis defense - was to be shared and analyzed by specialists using different analytic approaches. The idea was that bringing these different analytical angles to the same piece of data would allow for the emergence of a truly interdisciplinary understanding of language as social action. The video was made and circulated among committee members, but the project seems to have foundered over major disagreement about the meaning and value of the experiment. For many, such a decontextualized approach was simply impossible. One result, then, may well have been the end of the interdisciplinarity that characterized the early years of the committee, and a retreat into silos.

A final comment: I told this story (or a version of it) to a group of French sociolinguists. They remarked that the parallel in their careers was the CERM, 
the Centre d'études et de recherches marxistes, a network of centers set up by the French Communist Party. One, led by Marcel Cohen, was devoted to linguistics. This raises the question: Why was it the SSRC that led the way in the United States, and the French Communist Party in France? What other committee-type structures should we be looking for as we construct genealogies of ideas about language-culture-thought, their circulation, and their effects? What role have they played in foregrounding certain kinds of ideas (and their proponents), and sending others off to the metaphorical guillotine? Notably, how have they treated the inevitably political aspect of the ways in which language is bound up with the making of social difference and social inequality?

\section{References}

Fox, Melvin. 1975. Language and development: Retrospective survey of Ford Foundation language Projects 1952-1974. New York: Ford Foundation.

Gumperz, John \& Dell Hymes (eds.). 1991 [1972]. Directions in sociolinguistics: The ethnography of communication. New York: Wiley-Blackwell.

Article note: This essay was originally published in Items: Insights from the Social Sciences, a publication of the Social Science Research Council. Heller, Monica. "Scholarly Committees as Elite Public Action: The SSRC and the Origins of Sociolinguistics." Items: Insights from the Social Sciences. https://items.ssrc.org/insights/scholarly-committees-as-elite-public-actionthe-ssrc-and-the-origins-of-sociolinguistics/. Reprinted with permission.

This text draws on elements of Monica Heller and Bonnie McElhinny, Language, Capitalism, Colonialism: Toward a Critical History (University of Toronto Press, 2017) and Monica Heller, "Socioeconomic Junctures, Theoretical Shifts: A Genealogy of Language Policy and Planning Research," in The Oxford Handbook of Language Policy and Planning, eds. James Tollefson and Miguel Pérez-Milans (Oxford: Oxford University Press, 2018), 35-50. 